\title{
Cicloturismo como ferramenta de desenvolvimento sustentável em área rural: Desafios e oportunidades no processo de retomada pós-pandemia da COVID-19
}

\author{
Cycle tourism as a tool for sustainable development in rural areas: Challenges and \\ opportunities in the post-COVID-19 resumption process
}
El cicloturismo como herramienta para el desarrollo sostenible en la zona rural: desafíos y oportunidades en el proceso de recuperación pospandémica del COVID-19

Luiz Saldanha ${ }^{1}$

Carla Fraga ${ }^{2}$

Ronaldo Balassiano ${ }^{3}$

Artigo Selecionado - Edição especial Inovação e Empreendedorismo em Turismo: interação entre os diferentes atores

\begin{abstract}
Resumo: Ao se considerar o planejamento e a gestão de cicloturismo sob a ótica da sustentabilidade, as oportunidades e os desafios no processo de retomada do turismo pós-pandemia do COVID 19 são inúmeros. Portanto, o objetivo deste estudo é analisar especificamente o cicloturismo como ferramenta para o desenvolvimento sustentável de áreas rurais no Brasil. A pesquisa é exploratória e descritiva. A parte empírica deriva do cruzamento de dados secundários, obtidos de diversas fontes, sendo três passos: (a) mapeamento das rotas de cicloturismo consolidadas no Brasil antes da pandemia; (b) classificação e caracterização dos municípios abrangidos; e (c) contextualização dos resultados a partir da Agenda 2030 e Covid-19. Numa perspectiva holística, os resultados contribuem para se avançar em quatro temáticas: (1) aspectos normativos e regulação; (2) participação cidadã; (3) infraestrutura e serviços; e (4) gestão, controle e operação. Em síntese, compreende-se que a bicicleta, na interface do desenvolvimento do turismo sustentável, pode inclusive contribuir para conter um problema chave da globalização, qual seja o êxodo rural em municípios de até 5 mil habitantes, ou naqueles de até 20 mil habitantes. Resultados apontam para a função estratégica desempenhada por estes municípios na manutenção de rotas de cicloturismo já consolidadas na retomada do turismo pós-pandemia.
\end{abstract}

Palavras-chave: Cicloturismo. Desenvolvimento sustentável. Áreas rurais. Covid-19.

\begin{abstract}
Considering cycle tourism planning and management from the sustainability perspective, the opportunities and challenges in the COVID 19 post-pandemic tourism resumption process are numerous. Therefore, this study aims to specifically analyse cycle tourism as a tool for the sustainable development of rural areas in Brazil. The research is exploratory and descriptive. The empirical part derives from the crossing of secondary data, obtained from different sources throughout three steps: (a) mapping of cycle tourism routes consolidated in Brazil before the pandemic crisis; (b) classification and characterization of the municipalities covered; (c) contextualizing the obtained results through 2030 Agenda and Covid-19 context. From a holistic perspective, the results contribute to progress on four themes: (1) normative aspects and regulation; (2) citizen participation; (3) infrastructure and services; and (4) management, control, and operation. It is understood that the bicycle, within the interface of sustainable tourism development, can even contribute to containing a key issue of globalization: the rural exodus in municipalities with up to 5,000 inhabitants; or those with up to 20,000 inhabitants. Results point to the strategic role played by these municipalities in maintaining cycle tourism routes already consolidated in the resumption of post-pandemic tourism.
\end{abstract}

Keywords: Cycle tourism. Sustainable development. Rural areas. Covid-19.

Resumen: Al considerar la planificación y gestión del cicloturismo desde la perspectiva de la sostenibilidad, las oportunidades y desafíos en el proceso de reanudación del turismo pospandémico de COVID 19 son numerosos. Por tanto, el objetivo de este estudio es analizar específicamente el cicloturismo como herramienta para el desarrollo sostenible de las zonas rurales de Brasil. La investigación es exploratoria y descriptiva. La parte

\footnotetext{
${ }^{1}$ Formação/curso: Doutorando em Engenharia de Transportes. Instituição: Universidade Federal do Rio de Janeiro - UFRJ, Rio de Janeiro - RJ, Brasil. E-mail: luizsaldanha@pet.coppe.ufrj.br

${ }^{2}$ Formação/curso: Doutorado em Engenharia de Transportes. Instituição: Universidade Federal do Estado do Rio de Janeiro - UNIRIO, Rio de Janeiro - RJ, Brasil. E-mail: carla.fraga@ unirio.br

${ }^{3}$ Formação/curso: Doutorado em Engenharia de Transportes. Instituição: Universidade Federal do Rio de Janeiro - UFRJ, Rio de Janeiro - RJ, Brasil. E-mail: ronaldo@pet.coppe.ufrj.br
} 
CICLOTURISMO COMO FERRAMENTA DE

empírica deriva del cruce de datos secundarios, obtenidos de diferentes fuentes, con tres pasos: (a) mapeo de rutas de cicloturismo consolidadas en Brasil antes de la pandemia; (b) clasificación y caracterización de los municipios cubiertos; y (c) contextualizar los resultados de la Agenda 2030 y Covid-19. Desde una perspectiva holística, los resultados contribuyen al avance en cuatro temáticas: (1) aspectos normativos y de regulación; (2) participación ciudadana; (3) infraestructura y servicios; y (4) gestión, control y operación. En resumen, se entiende que la bicicleta, en la interfaz del desarrollo turístico sostenible, puede incluso contribuir a contener un problema clave de la globalización, que es el éxodo rural en municipios de hasta 5.000 habitantes, o en aquellos de hasta 20.000 habitantes. Los resultados apuntan al papel estratégico de estos municipios en el mantenimiento de rutas de cicloturismo ya consolidadas en la reanudación del turismo pospandémico.

Palabras Clave: Cicloturismo. Desarrollo sostenible. Zonas rurales. Covid-19.

\section{Introdução}

Após considerar a desaceleração forçada da atividade turística em consequência da pandemia do novo coronavírus (COVID-19), Milano e Koens (2021) apontaram a janela de oportunidade política introduzida pela crise pandêmica para habilitar uma recuperação do turismo de modo equilibrado por meio de estratégias de médio a longo prazo visando a consolidação e reposicionamento de destinos. Caso isso não seja levado em consideração, destacam que a falta de políticas consistentes pode acarretar no declínio destes destinos, ampliando conflitos entre visitantes e residentes e impactando diretamente o meio ambiente nestas localidades. No Brasil, conforme observado por Fontoura, Lusby e Romagosa (2020), a retomada da atividade turística é notada ainda na segunda metade de 2020, com destaque para um turismo regionalizado, optando-se ao envolvimento de áreas rurais, atividades ao ar livre e na natureza e maior contato com comunidades locais. Apesar de indicar os benefícios econômicos a estes destinos anteriormente menos procurados, os autores denotam a importância da preparação e do planejamento na condução da atividade turística para não acarretar experiências negativas para ambas as partes envolvidas ou em impactos irreversíveis no ambiente.

Entende-se que o próprio conceito de desenvolvimento sustentável precisa ser reinventado. A Sociedade Brasileira para o Progresso da Ciência (SBPC) tratou em evento recente o tema "Todas as Ciências são Humanas e Essenciais à Sociedade" " e, quando se tem uma crise sanitária que coloca vidas humanas em risco, é necessário que toda e qualquer discussão sobre turismo e desenvolvimento sustentável em perspectiva científica seja uma discussão sobre humanidades. A razão deste artigo não se insere apenas numa demonstração socioespacial de desafios e oportunidades para desenvolvimento rural. Centra-se, também, nas questões humanas inerentes à união entre Ciências e Tecnologias para

\footnotetext{
${ }^{4}$ A $73^{\text {a }}$ Reunião Anual da SBPC ocorreu virtualmente em julho de 2021 - Transmissão pelo canal da SBPC no Youtube, sendo uma realização em parceria com a Universidade Federal de Juiz de Fora (SBPC, 2021).
}

Revista Acadêmica Observatório de Inovação do Turismo, v. 15, n. 3, dezembro/2021 
avanços disciplinares diversos, rompendo a própria disciplinaridade, indo ao encontro do pósdisciplinar.

Desta forma, busca-se refletir sobre como a relação entre bicicleta e turismo poderá de fato contribuir para o desenvolvimento sustentável em áreas rurais - sem que seja um exercício de futurologia do pós-pandemia. Logo, o objetivo geral é analisar o cicloturismo como ferramenta para o desenvolvimento sustentável de áreas rurais no Brasil, diante de desafios e oportunidades que emergem do que poderá ser o pós-pandemia. Quanto aos objetivos específicos, estes são: (a) identificar a relação entre urbano e rural na dinâmica do cicloturismo, pelo bojo da sustentabilidade; (b) mapear as rotas de cicloturismo no Brasil pré-pandemia; e (c) considerando a geomorfologia de destinos, analisar as rotas brasileiras e caracterizar a contribuição de seus respectivos pontos (origem, destinos, hubs) para o desenvolvimento de áreas rurais na perspectiva do cicloturismo.

Esta pesquisa é exploratória e descritiva, estruturada da subsequente forma: fundamentação teórico-conceitual para apresentar a metodologia, resultados e discussões. Nestes, considera-se a categorização de municípios do Mapa do Turismo (2019-2021) como referência (BRASIL, 2021), bem como a tipologia municipal rural-urbano (IBGE, 2017).

\section{Cicloturismo em áreas rurais e a sustentabilidade}

Antes da crise ocasionada pela pandemia do COVID-19, a revisão sistemática realizada por Veríssimo et al. (2020) destacou os conflitos inerentes aos impactos negativos do turismo e são sintetizados na Tabela 1. Estes conflitos, distribuídos pelas dimensões econômica, social e ambiental/estrutural, implicam na necessidade de estabelecer estratégias para gerenciamento dos excessos ocasionados pelo turismo. De acordo com os próprios autores, é importante a implementação de políticas que visem a diminuição na diferença entre baixa e alta temporadas (sazonalidade), a descentralização das tomadas de decisão entre os atores da sociedade, a diversificação da oferta turística e o descongestionamento das vias e espaços públicos. 
Tabela 1 - Impactos negativos do turismo nos destinos

\begin{tabular}{cl}
\hline Dimensão & \multicolumn{1}{c}{ Impactos negativos do turismo nos destinos } \\
\hline Econômica & - Aumento do número de acomodações de curto prazo \\
& - Aumento do preço da terra e de habitações \\
& - Aumento dos preços devido a serviços e produtos orientados a turistas \\
& - Problemas relacionados à sazonalidade (falta de empregos e de renda durante a baixa \\
& temporada). \\
\hline Social & - Conflitos sociais de diferentes grupos de interesse; \\
& - Geração de desigualdades e marginalização de grupos locais; \\
& - Perda de população local vivendo nos centros históricos; \\
& - Necessidade de resiliência comunitária; \\
& - Redução da qualidade de vida; \\
& - Choque cultural (turistas de diferentes culturas e comportamentos). \\
\hline Ambiental / & - Ameaças a espécies locais e a sítios geológicos; \\
estrutural & - Emissão de GEE e poluição do ar; \\
& - Congestionamento, falta de espaços e locais superlotados; \\
& - Piora da segurança pública e limpeza da cidade; \\
& - Problemas de uso do solo. \\
\hline
\end{tabular}

Fonte: Adaptado de Veríssimo et al. (2020).

A categorização de destinos turísticos é complexa, pois pode abranger áreas geográficas diversas (LOHMANN; PANOSSO NETTO, 2008). Contudo, ao se considerar as dimensões econômica, social, ambiental/estrutural é possível criar um parâmetro que seja útil tanto para as perspectivas temporais variadas, inclusive aquelas que são entrecortadas pela pandemia da COVID-19, quanto para a implicância de termos como "novo normal", ligando-se às continuidades e descontinuidades da relação entre real, virtual e imaginado (LÉVY, 1996), antes, durante e pós pandemia da COVID-19. Ao considerar os impactos negativos do turismo nos destinos, é essencial compreender a instrumentalização de modos ativos de deslocamento como estratégia de desenvolvimento sustentável. Isto é principalmente importante para cidades de pequeno porte e áreas rurais situadas em destinos turísticos.

O esquema da Figura 1 demonstra os níveis de sustentabilidade relativos aos modos de transportes, o que caracteriza a relação estreita entre transporte e sustentabilidade, uma vez que não existe turismo sustentável sem transporte sustentável (WIECKOWSKI, 2021; PALHARES, 2005). 
CICLOTURISMO COMO FERRAMENTA DE

Figura 1 - Transportes e sustentabilidade

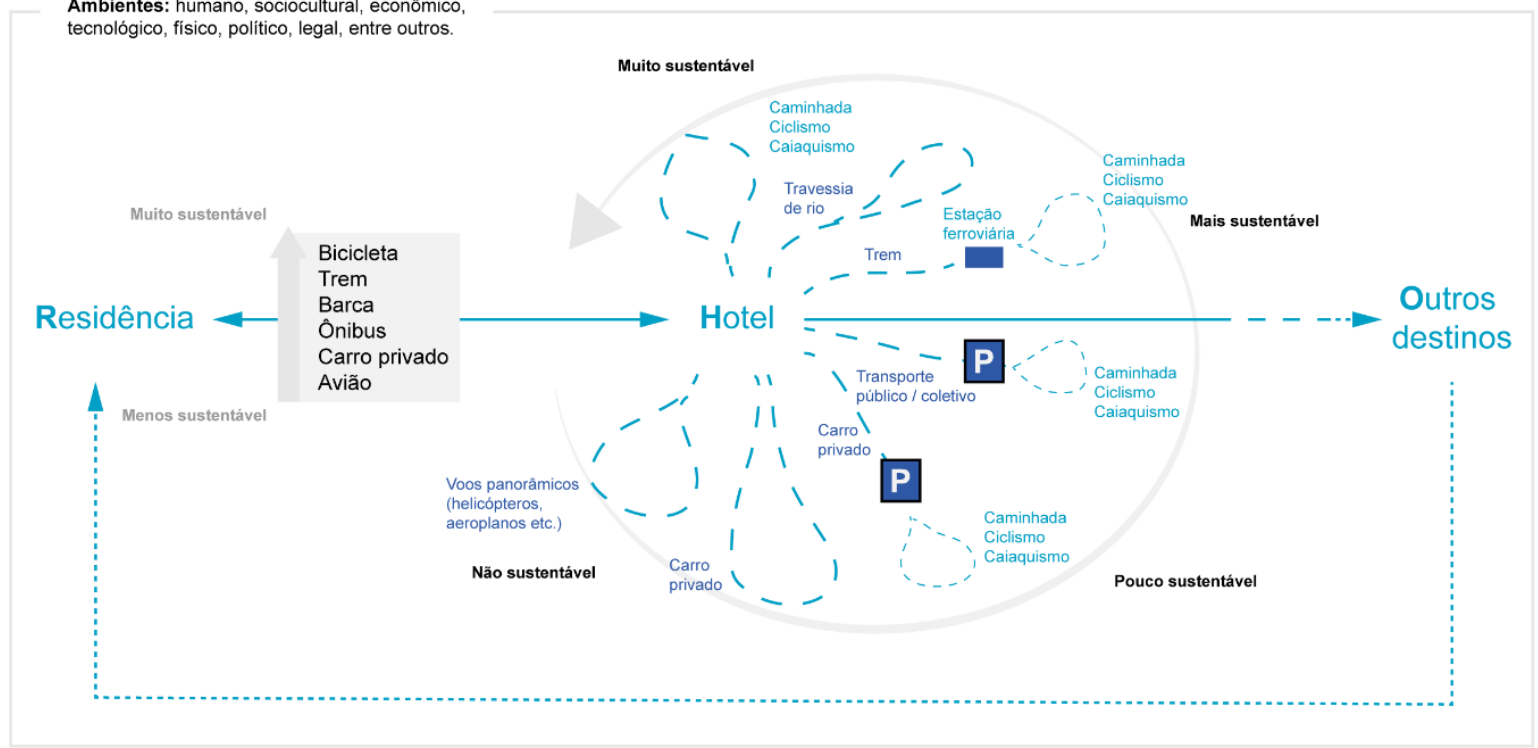

Fonte: Adaptado pelos autores a partir de Wieckowski (2021); Palhares (2005).

A partir do esquema apresentado na Figura 1, a visão sistêmica, que é paradigmática para tratar o turismo (LOHMANN; PANOSSO NETTO, 2008) também contribui para os avanços que equacionam transportes, turismo e sustentabilidade, sendo que para o cicloturismo, as políticas cicloinclusivas têm uma dimensão fundamental como balizadoras das práticas (SALDANHA, 2017). Políticas cicloinclusivas, segundo o BID (2015), são aquelas que visam integrar o uso da bicicleta no sistema de transportes como um todo a partir de abordagens nas áreas temáticas expostas na Tabela 2. Assim, resgata-se a conceituação sobre cicloturismo e suas tipologias de destino em relação às características locais (urbanização/ruralidade, áreas protegidas e quantidade de municípios envolvidos etc.).

Lohmann e Duval (2014) já tinham sinalizado a influência direta da geomorfologia de destinos no desenvolvimento da relação entre transportes e turismo, sendo as categorias analisadas pelos autores ilhas e arquipélagos, centros urbanos, montanhas e áreas rurais. Especificamente sobre áreas rurais, os autores explicam que são difíceis de classificar precisamente, mas que as suas características particulares influenciam nas escolhas de transporte sustentável. Além das atividades recreacionais, muitas destas áreas podem ser isoladas, sem rotas de transportes público, além de estarem suscetíveis a sazonalidade (baixa e alta temporadas). Fraga, Santos e Ribeiro (2013) detalharam como é relevante construir perguntas de pesquisa sobre áreas rurais, transportes e turismo e relatam dois eixos de análises: um sobre o próprio sentido do turismo rural, e o segundo sobre a relação entre transporte e turismo na perspectiva do desenvolvimento e da sustentabilidade. A visão apresentada na Figura 1 possibilita discutir, junto às 
CICLOTURISMO COMO FERRAMENTA DE

ÁREA RURAL: DESAFIOS E OPORTUNIDADES

NO PROCESSO DE RETOMADA PÓS-

PANDEMIA DA COVID-19

políticas cicloinclusivas e as tipologias de destinos e caracterizações locais, como a instrumentalização do cicloturismo pode ocorrer para o desenvolvimento sustentável de áreas rurais.

Tabela 2 - Áreas temáticas das políticas cicloinclusivas

\begin{tabular}{l|l}
\hline \multicolumn{1}{c|}{ Área temática } & \multicolumn{1}{c}{ Descrição } \\
\hline Aspectos normativos e regulação & $\begin{array}{l}\text { Políticas públicas que fomentam e regulam o uso da bicicleta, } \\
\text { estabelecendo desde a hierarquia entre os modos de transportes ativos e } \\
\text { motorizados até a articulação intersetorial entre desenhos de } \\
\text { infraestrutura e operação de serviços complementares. }\end{array}$ \\
\hline Participação cidadã & $\begin{array}{l}\text { Implementação de estratégias participativas no processo de } \\
\text { planejamento cicloviário de forma a envolver usuários, não-usuários, } \\
\text { órgãos públicos e outros atores-chave relacionados direta e } \\
\text { indiretamente. }\end{array}$ \\
\hline Infraestrutura e serviços & $\begin{array}{l}\text { Características físicas estruturais necessárias para garantir uma rede } \\
\text { cicloviária segura e confortável aos usuários. Denota-se que esta } \\
\text { temática não se restringe apenas às vias de circulação de ciclistas, mas } \\
\text { também abrange o desenvolvimento de facilidades como } \\
\text { estacionamentos e oficinas de reparo, por exemplo. }\end{array}$ \\
\hline Gestão, controle e operação & $\begin{array}{l}\text { Para além da gestão, controle e operação de sistemas de transportes } \\
\text { cicloviários, inclui-se, a esta temática, o foco na integração a outros } \\
\text { modos de transporte e no monitoramento de dados relacionados ao uso } \\
\text { da bicicleta. }\end{array}$ \\
\hline
\end{tabular}

Fonte: Elaboração própria com base em BID (2015).

O cicloturismo, em sua essência, contempla quaisquer atividades realizadas por bicicleta para fins de turismo e lazer - incluindo passeios sem pernoite dentro ou fora do local de residência até viagens com um ou mais pernoites por diversos municípios (LEE, 2014; SARTORI, 2020). Relaciona-se a Figura 1 aos conceitos de Lohmann e Duval (2014) para a configuração do cicloturismo entre centros urbanos às áreas rurais e naturais. Os centros urbanos são considerados como os principais polos dispersores de cicloturistas para as áreas rurais e naturais dentro da dinâmica das rotas de cicloturismo, podendo variar de tamanho, densidade populacional e infraestrutura turística e básica (SALDANHA et al., 2020). Diferentes modelos são debatidos e utilizados para o planejamento destes centros urbanos para melhor favorecer o desenvolvimento das comunidades rurais do entorno e a conservação das paisagens e ecossistema natural, sempre considerando elementos como: serviços de hospedagem, serviços de reparo e locação/compra de equipamentos, acomodações, estabelecimentos de alimentação, infraestrutura viária e de sinalização, sistemas de informação, atrativos e entretenimento, serviços de turismo receptivo e serviços básicos (WESTCYCLE, 2016).

Concernente à ressignificação do meio rural, Sousa e Carvalho (2021) apontam o papel do cicloturismo ao considerá-lo como mobilidade turística sustentável na promoção dos patrimônios 
ambientais e das identidades culturais, dinamizando práticas não-agrícolas e fortalecendo laços de afetividade e pertencimento entre os habitantes e seus locais de residência. Inclusive, ressaltam a dinamicidade entre os meios rural e urbano em trocas comerciais e deslocamentos pendulares na região do Baixo Parnaíba Maranhense para a composição de roteiros de cicloturismo.

Em convergência ao caso do Maranhão, destacam-se dois estudos nacionais que visam o cicloturismo como ferramenta para potencializar o turismo rural por meio da mobilidade sustentável. No primeiro, de Carvalho, Ramos e Sydow (2013), os autores vislumbraram a atividade para estabelecer o novo paradigma do turismo sustentável à população e poder público na região de Araguaína, Tocantins, contribuindo para a geração de renda e oportunidades de novos negócios (principalmente no período de baixa temporada), além da melhora na infraestrutura de turismo e de transportes nas cidades envolvidas. Já o segundo, de Sartori (2020), debate como a realização de eventos ciclísticos com transições entre o centro urbano e as áreas rurais do município de Nova Trento, Santa Catarina, foi crucial para o desenvolvimento de uma rota de cicloturismo na região, especialmente ao engajar a população residente sobre seus benefícios econômicos e ambientais - além de consolidar percursos e paisagens apresentadas aos visitantes a cada edição do evento.

No entanto, a necessidade de políticas públicas e de estratégias para desenvolvimento sustentável da atividade turística são ressaltadas pelos três estudos supracitados e, caso não sejam consideradas, é possível acarretar sucessivos impactos negativos à comunidade receptora, conforme preveem Milano e Koens (2021), conforme é exemplificado na Tabela 1. A articulação institucional é tratada como fundamental por Sousa e Carvalho (2021) para a qualidade da experiência turística em áreas rurais ao prever estratégias de diversificação da oferta turística, promoção do destino, consolidação de um calendário de eventos e capacitação aos prestadores de serviços de turismo e hospitalidade. Ao mesmo tempo, Carvalho, Ramos e Sydow (2013) pontuaram a importância do cicloturismo para fomentar o investimento em infraestrutura rodoviária, comércio e serviços de turismo e apoio (meios de hospedagem, estabelecimentos de alimentação e meios de transportes). Ainda, a participação popular é evidenciada por Sartori (2020) como atributo substancial no planejamento e gestão de roteiros para a recepção de uma demanda diversificada, que busca maior interação com a natureza e intercâmbios culturais, porém com estrutura adequada para garantia de suporte e segurança.

De acordo com Tulik (2004), o turismo em áreas rurais é bastante diversificado e, nesse sentido, a união entre cicloturismo e turismo rural deve considerar uma série de nuances que não sejam só aquelas focadas nos atributos de cada segmento, mas naquilo que de fato forma o micro nicho. Portanto, para o planejamento e gestão da interface entre transportes, turismo e sustentabilidade, recorre-se às noções de 
funções nodais e de rede de transportes, pois são imprescindíveis para se identificar os hubs (nós, nas redes de transportes) e as rotas (vetores que envolvem vários padrões de deslocamento variados), sendo essencial à compreensão teórico conceitual imbricada à Figura 1.

\section{Metodologia}

O estudo é exploratório e descritivo, de natureza qualitativa, sendo realizado a partir de levantamento bibliográfico para a construção de categorias de análises frente à problemática apresentada nos desafios e oportunidades do cicloturismo enquanto ferramenta de desenvolvimento sustentável em áreas rurais brasileiras. O software QGis 3.12 foi utilizado como apoio para georreferenciamento nas etapas detalhadas a seguir.

\subsection{Mapeamento das rotas de cicloturismo consolidadas pré-pandemia}

Sob a perspectiva da adaptação do sistema de turismo de Leiper para dinâmicas do cicloturismo por Lamont (2009), temos a configuração da atividade para sua prática intradestinos ou entre regiões de destinos. Em justaposição ao modelo de transportes e turismo de Palhares (2005), este trabalho optou por delimitar rotas de cicloturismo que conectam destinos primários e secundários dentro de todo o contexto da viagem. Desconsidera-se, assim, roteiros e trilhas que se distribuem dentro de um mesmo destino sem considerar a necessidade de pernoite para que sejam realizados.

Além do desafio de definição de métricas para delimitação de rotas autodeclaradas ativas para realização de viagens por bicicletas e consolidadas antes da pandemia causada pela COVID-19, foi necessário o levantamento de diversos destinos de cicloturismo para chegar ao montante final por meio da filtragem. Em abril de 2020, a identificação inicial de rotas de cicloturismo teve base nos dados obtidos pelos respondentes da pesquisa "O Cicloturista Brasileiro 2018" (SALDANHA et al., 2019). Na sequência, houve o balizamento pela verificação de portais de notícias e reportagens de abrangência nacional especializados na temática de cicloturismo - a saber: Revista Bicicleta (2020), Clube de Cicloturismo do Brasil (2020) e Ciclotur Experience (2020). Concomitantemente, o levantamento foi complementado pelo contexto de roteiros para peregrinações não diretamente envolvidas no cicloturismo, tendo em vista a representatividade observada entre as 591 respostas da pesquisa $O$ Cicloturista Brasileiro 2018. Nesta dinâmica, delimitou-se o portal Peregrinos Sem Fronteiras (PSF, 2020) devido à sua compilação de roteiros envolver a maior interseção entre o universo considerado. 
CICLOTURISMO COMO FERRAMENTA DE

Subsequentemente, os seguintes critérios de validação para cada uma das 189 rotas inicialmente levantadas foram definidos e analisados a partir da autodeclaração presente em suas respectivas páginas oficiais de contato com o público geral: (1) lançamento oficial até o final do ano de 2019; (2) existência de website próprio, incorporado ou de rede social ativa semanalmente; (3) apontamento para uso da bicicleta no percurso, caso não seja uma rota exclusiva para o cicloturismo; (4) indicação para a realização de pernoites; (5) indicação de contato de referência; (6) indicação de como realizar de forma totalmente autônoma ou de como contratar para a realização guiada e autoguiada.

Para a produção deste artigo, uma nova validação no dia 13 de julho de 2021 foi feita para atualização das rotas ativas. Por fim, uma análise sobre as páginas oficiais de cada rota foi realizada para compreender as respectivas extensões apresentadas e os municípios abrangidos.

\subsection{Classificação e caracterização dos municípios abrangidos}

De acordo com IBGE (2017), três tipologias rural-urbana de municípios são passíveis de classificação para o contexto brasileiro: (1) predominantemente urbano; (2) intermediário; e (3) predominantemente rural. Identifica-se, na Tabela 3, como os municípios se classificam em cada tipologia rural-urbana por meio da verificação de sua população residente em área de ocupação densa e seu respectivo grau de urbanização. Aos municípios classificados como intermediário e rural, contempla-se também a caracterização de adjacentes e remotos. Isso ocorre em relação à proximidade geográfica a centros urbanos de maior hierarquia (IBGE, 2017).

Tabela 3 - Grau de urbanização por tipologia rural-urbana e por população em área de ocupação densa Municípios em Unidades Populacionais Grau de urbanização por tipologia rural-urbana

\begin{tabular}{lccc}
\hline População em área de ocupação densa & Urbano & Intermediário & Rural \\
\hline Entre 3 mil e 10 mil habitantes & - & Superior a 75\% & Inferior a 75\% \\
\hline Entre 10 mil e 25 mil habitantes & Superior a $75 \%$ & Entre $50 \%$ e $75 \%$ & Inferior a 50\% \\
Entre 25 mil e 50 mil habitantes & Superior a 50\% & Entre 25\% e 50\% & Inferior a 25\% \\
Acima de 50 mil habitantes & Todos & - & - \\
Total de municípios por tipologia & $\mathbf{1 . 4 5 6}$ & $\mathbf{7 4 6}$ & $\mathbf{3 . 3 6 3}$ \\
\hline
\end{tabular}

Fonte: Elaboração própria com base em IBGE (2017).

A partir da Tabela 3 é relevante considerar o Mapa do Turismo Brasileiro (BRASIL, 2019; 2021) e a categorização dos municípios (de A até E) conforme cinco variáveis: (1) quantidade de estabelecimentos de hospedagem; (2) quantidade de empregos em estabelecimentos de hospedagem; (3) 
quantidade estimada de visitantes domésticos; (4) quantidade estimada de visitantes internacionais; e (5) arrecadação de impostos federais a partir dos meios de hospedagem.

\subsection{Contextualização dos resultados a partir da Agenda 2030 e Covid-19}

A partir da preocupação com a ampliação da longevidade dos recursos naturais e culturais da terra e com a melhora da qualidade de vida de toda sua população, principalmente os grupos mais vulneráveis, como povos tradicionais, idosos, crianças e mulheres, a Organização das Nações Unidas estabeleceu 17 Objetivos de Desenvolvimento Sustentável (ODS) para orientação da Agenda 2030 (ONU, 2015). No debate sobre os efeitos da pandemia da COVID-19 na América Latina e Caribe apresentados por Bárcena (2020), o retrocesso da pobreza neste período para índices de 14 anos anteriores trouxe reflexões para uma transformação urgente na construção de economias inclusivas e sustentáveis.

As oportunidades expostas a partir das dinâmicas de cada ODS são discutidas frente ao desafio em escala mundial que a população deve atravessar. Com isso, Bárcena (2020) propõe estratégias pautadas nos princípios da Agenda 2030, com o objetivo de analisar as regiões sob a luz do desenvolvimento local para avançar a uma integração produtiva, comercial e tecnológica, além de buscar soluções baseadas na natureza. Ao assumir que a Agenda 2030 permite diferentes abordagens e que os documentos disponíveis trazem diferentes perspectivas por ODS, a complexidade intersetorial envolvida na atividade do cicloturismo implica na necessidade de investigar agendas dedicadas à perspectiva da bicicleta e do turismo em espaços rurais. Desta forma, os resultados das incursões apresentadas nos itens 3.1 e 3.2 serão utilizados como base da discussão sobre a construção de ambientes favoráveis para o cicloturismo no Brasil.

Orientada pelas áreas temáticas das políticas cicloinclusivas expostas na Tabela 2, esta discussão visa alinhar, no que implica a retomada do turismo pós-pandemia, as fundamentações sobre a Agenda 2030 nos seguintes aspectos: (a) desenvolvimento do turismo em áreas rurais (OMT, 2020a) e (b) ciclismo como instrumento de desenvolvimento socioeconômico e redução de impactos ambientais (ECF, 2016; UCB, 2016). 


\section{Resultados e discussões}

Embora seja complexo definir o turismo rural (TULIK, 2004) e a própria relação entre o turismo em áreas rurais e os transportes (LOHMANN; DUVAL, 2014), o somatório das discussões desses resultados possibilita delinear desafios e oportunidades para o cicloturismo no contex to de retomada do desenvolvimento sustentável de destinos turísticos rurais no Brasil.

\subsection{Identificação e mapeamento das rotas de cicloturismo consolidadas antes da pandemia}

Conforme observado, o planejamento e a gestão de destinos turísticos a partir da sinergia entre turismo e bicicleta é algo complexo, envolvendo o que, na estrutura de Lohmann e Duval (2014), é chave para compreender a relação entre turismo e transportes: as abrangências geomorfológicas distintas, como as áreas rurais. Ao funcionalizar o desenvolvimento de rotas, estas podem ser ou não consolidadas em função das escolhas que objetivem o desenvolvimento sustentável tanto do segmento quanto dos destinos envolvidos. Considerando que a pandemia causada pela COVID-19 é um marco temporal que coloca em perspectiva toda e qualquer noção sobre desenvolvimento sustentável, torna-se essencial um diagnóstico situacional por meio do mapeamento das rotas de cicloturismo antes da pandemia.

A delimitação proposta no item 3.1 identificou 31 rotas autodeclaradas ativas e lançadas até o final de 2019 - e estão dispostas na Tabela 4. 
CICLOTURISMO COMO FERRAMENTA DE

ÁREA RURAL: DESAFIOS E OPORTUNIDADES

NO PROCESSO DE RETOMADA PÓS-

PANDEMIA DA COVID-19

Tabela 4 - Detalhamento das rotas autodeclaradas ativas e lançadas pré-pandemia identificadas

\begin{tabular}{|c|c|c|c|c|}
\hline $\mathbf{U F}$ & Nome da rota & Ano & Extensão (km) & Municípios \\
\hline $\mathrm{MG}, \mathrm{SP}, \mathrm{RJ}$ & Estrada Real & 1999 & 1780,0 & 68 \\
\hline MG & Caminho da Luz & 2001 & 200,0 & 9 \\
\hline $\mathrm{RS}$ & Caminho das Missões & 2002 & 467,0 & 5 \\
\hline SP & Caminho do Sol & 2002 & 241,0 & 11 \\
\hline $\mathrm{SP}, \mathrm{MG}$ & Caminho da Fé & 2003 & 970,0 & 70 \\
\hline $\mathrm{SC}$ & Circuito do Vale Europeu & 2006 & 280,0 & 12 \\
\hline $\mathrm{ES}$ & Caminho da Sabedoria & 2007 & 108,0 & 1 \\
\hline $\mathrm{SC}$ & Circuito Costa Verde e Mar & 2008 & 212,1 & 10 \\
\hline $\mathrm{SC}$ & Acolhida na Colônia & 2009 & 116,0 & 2 \\
\hline MG & Caminho de Aparecida & 2011 & 280,0 & 18 \\
\hline $\mathrm{SC}$ & Circuito das Araucárias & 2012 & 248,0 & 4 \\
\hline SP & Caminho do Sal & 2014 & 50,0 & 3 \\
\hline MG & Caminhos de Rosa & 2014 & 266,6 & 5 \\
\hline $\mathrm{RS}$ & Cascatas e Montanhas & 2014 & 123,0 & 3 \\
\hline MG & Trilha Verde da Maria Fumaça & 2014 & 92,0 & 7 \\
\hline MG & Caminho da Prece & 2015 & 71,0 & 5 \\
\hline $\mathrm{SP}, \mathrm{PR}$ & Circuito Lagamar & 2015 & 326,0 & 6 \\
\hline MG & Volta das Transições & 2016 & 340,0 & 10 \\
\hline SP & Rota da Luz SP & 2016 & 201,0 & 9 \\
\hline SP & Caminho da Paz SP & 2017 & 381,0 & 11 \\
\hline GO & Caminho de Cora Coralina & 2017 & 300,0 & 8 \\
\hline $\mathrm{MG}, \mathrm{SP}$ & Caminho Religioso da Estrada Real (CRER) & 2017 & 828,4 & 38 \\
\hline RS & Caminho Pomerano & 2018 & 111,0 & 1 \\
\hline MG & Circuito Caminho dos Anjos & 2018 & 247,0 & 13 \\
\hline $\mathrm{RS}$ & Via Ecológica da Serra dos Tapes & 2018 & 114,0 & 2 \\
\hline MG & Caminho de Nhá Chica & 2019 & 260,0 & 16 \\
\hline SP & Caminho pro Interior & 2019 & 77,8 & 5 \\
\hline RS & Caminhos de Caravaggio & 2019 & 188,8 & 5 \\
\hline $\mathrm{SC}$ & Circuito de Cicloturismo Vale dos Encantos & 2019 & 499,22 & 6 \\
\hline $\mathrm{SC}$ & Vale Sagrado Cicloturismo & 2019 & 68,4 & 1 \\
\hline \multirow[t]{2}{*}{$\mathrm{SC}$} & Circuito Cicloturístico Cidade das Praias & 2019 & 163,0 & 4 \\
\hline & Total & & $9.409,32^{2}$ & $291^{3}$ \\
\hline
\end{tabular}

${ }^{1}$ Informações obtidas pela página oficial de cada rota em portais da internet ou rede social.

${ }^{2}$ Extensão de vias autodeclaradas pelas páginas oficiais das rotas, não necessariamente possuem infraestrutura segura e adequada para o ciclismo.

${ }^{3}$ Este valor considera a sobreposição dos municípios envolvidos na rota e não na simples soma dos municípios por rota.

Fonte: Elaboração própria (2021).

Revista Acadêmica Observatório de Inovação do Turismo, v. 15, n. 3, dezembro/2021 
CICLOTURISMO COMO FERRAMENTA DE

ÁREA RURAL: DESAFIOS E OPORTUNIDADES

NO PROCESSO DE RETOMADA PÓS-

PANDEMIA DA COVID-19

Na Tabela 4, a compilação das informações básicas sobre estas rotas denota que são quase 9,5 mil quilômetros de extensão em 291 municípios envolvidos - sendo que as Unidades Federativas (UF) de maior concentração estão localizadas nas regiões Sul e Sudeste do Brasil. A distribuição espacial dessas rotas ao longo do território brasileiro está apresentada na Figura 2. Nota-se que há a representação não apenas da localização geográfica a partir dos municípios de referência indicados nas páginas oficiais de cada rota identificada, mas também a síntese sobre o panorama geral entre as regiões brasileiras na recuperação dos critérios metodológicos para o recorte sobre estas rotas.

Figura 2 - Rotas de cicloturismo consolidadas pré-pandemia

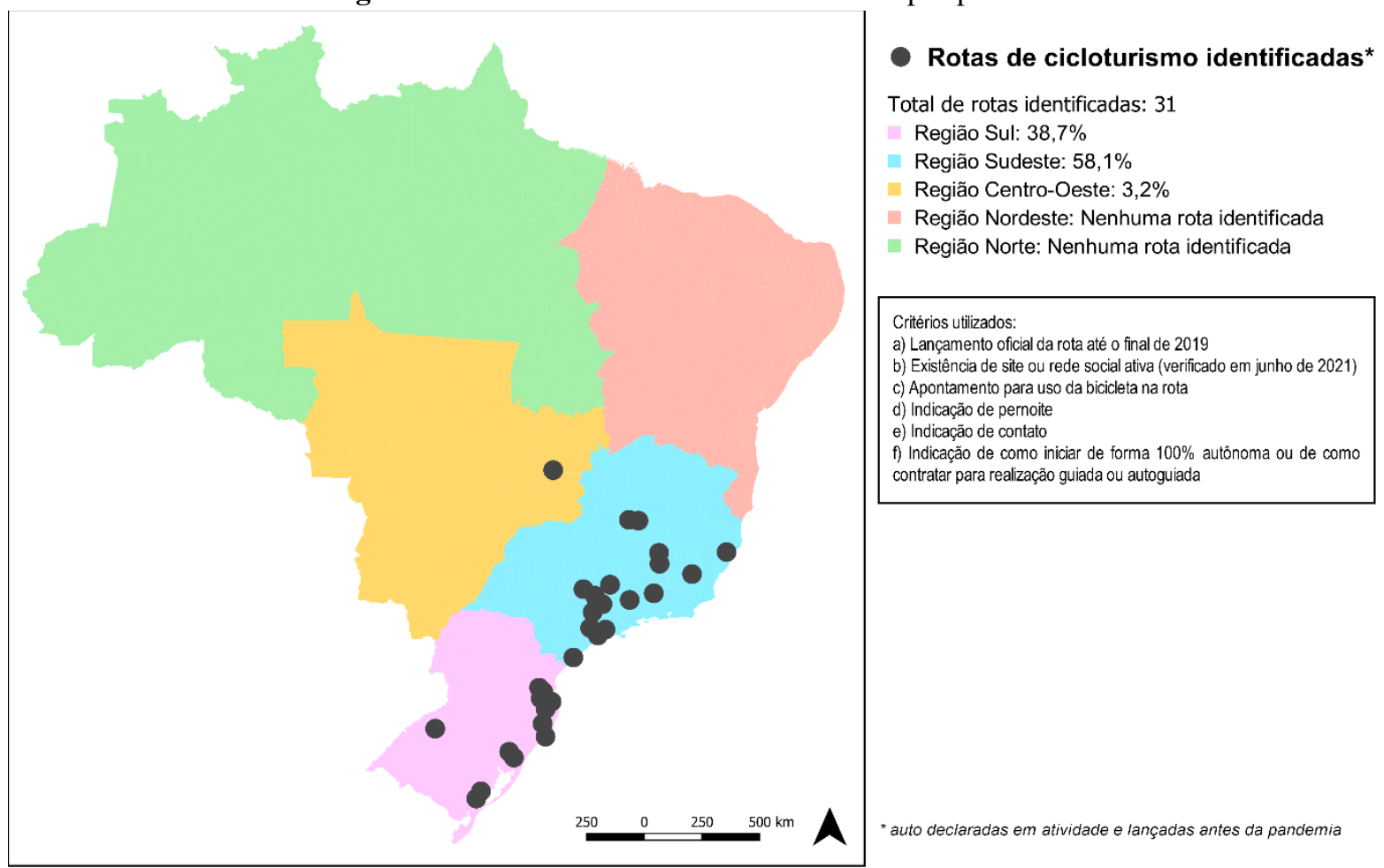

Fonte: Elaboração própria (2021).

O Caminho de Cora Coralina (GO) foi a única rota identificada, por meio dos critérios estabelecidos, que não se encontra nas regiões Sul e Sudeste. O que não implica em falta de iniciativas existentes nas UF das regiões Norte e Nordeste - inclusive, exemplos de estudos no Maranhão e em Tocantins foram expostos na seção 2 (SOUZA; CARVALHO, 2021; CARVALHO; RAMOS; SYDOW, 2013). Entre as sete UF das regiões Sul e Sudeste, a representatividade das rotas se faz nos estados de Minas Gerais (35,5\%), São Paulo (29,0\%), Santa Catarina (22,6\%) e Rio Grande do Sul (16,1\%). 
CICLOTURISMO COMO FERRAMENTA DE

ÁREA RURAL: DESAFIOS E OPORTUNIDADES

NO PROCESSO DE RETOMADA PÓS-

PANDEMIA DA COVID-19

A região Sudeste, por si só, apresenta algumas condições favoráveis à produção e atração de fluxos turísticos nacionais, já que abrange as três regiões metropolitanas mais populosas do país - as quais somam, juntas, quase um quinto de toda a população brasileira (IBGE, 2020). Ademais, das 28 regiões metropolitanas registradas pelo próprio IBGE (que considera, também, Regiões Integradas de Desenvolvimento e Aglomerações Urbanas com mais de um milhão de habitantes), onze envolvem municípios da região Sudeste, sendo sete no estado de São Paulo. Implicam-se às grandes concentrações urbanas funções nodais das redes de transporte por terminais de entrada de grande relevância, além de polos hoteleiros, serviços turísticos e densidades populacionais com grande potencial para produção de viagens com fins de turismo e lazer.

Destaca-se, para o estado de Santa Catarina, a priorização do cicloturismo como principal motivação para a construção das rotas. Enquanto parte das rotas da Tabela 4 tiveram seu desenvolvimento a partir de modos como caminhada ou mesmo de modos motorizados, seis entre as sete rotas catarinenses identificadas foram desenvolvidas a partir do cicloturismo - e, eventualmente, integraram outros modos de transporte na diversificação da oferta como produto turístico.

Quando a abordagem se faz pelo cicloturismo, indaga-se sobre qual o papel que os municípios assumem nos destinos pela variedade de escolhas sobre combinações modais envolvendo os diversos padrões de deslocamentos apresentados na Figura 1. Ao lado do turismo rural, a discussão sobre sustentabilidade aliando transportes e geomorfologia de destinos inclui não só a classificação turística do município (e os respectivos impactos econômico do setor, pela categorização no Mapa do Turismo), mas também os aspectos relativos à ruralidade em si.

\subsection{Incursão sobre ruralidades dos destinos de cicloturismo}

Recupera-se, para este item, a sinergia entre transportes e áreas rurais que implicam em uma série de fatores como o próprio isolamento geográfico, questões relativas ao provimento de transporte público e as possibilidades de atividades diversas nestes destinos e entre esses destinos (LOHMANN; DUVAL, 2014). Na busca pela experiência, por meio da perspectiva do cicloturismo, o espaço se integra ao produto turístico em formas de narrativas, nas quais esse isolamento geográfico se transforma de barreira para desenvolvimento econômico em um catalisador de benefícios socioambientais (MOSCARELLI apud SALDANHA et al., 2021). Desta forma, a Tabela 5 resulta do cruzamento entre os municípios mapeados para todas as rotas identificadas e as respectivas informações sobre categorização do Mapa do Turismo (BRASIL, 2021) e da tipologia rural-urbana oriunda do grau de 
CICLOTURISMO COMO FERRAMENTA DE

ÁREA RURAL: DESAFIOS E OPORTUNIDADES

NO PROCESSO DE RETOMADA PÓS-

PANDEMIA DA COVID-19

urbanização do IBGE (2017). Por meio destas informações, a agregação se faz por tamanho (em números de habitantes) para caracterizar a relação rural-urbana e a categorização (ou sua ausência) dos municípios integrantes das rotas de cicloturismo identificadas para este trabalho. Há, inclusive, o grifo sobre as linhas referentes à tipologia "rural adjacente" para facilitação da leitura sobre os dados.

Tabela 5 - Relação urbano x rural

\begin{tabular}{|c|c|c|c|c|c|c|c|}
\hline Demografia (em habitantes) & Total & $\mathbf{A}$ & $\mathbf{B}$ & $\mathrm{C}$ & $\mathbf{D}$ & $\mathbf{E}$ & $\mathrm{N} / \mathrm{C}$ \\
\hline Até 5 mil habitantes & 55 & - & - & $0,7 \%$ & $5,2 \%$ & $5,2 \%$ & $7,9 \%$ \\
\hline Rural Adjacente & 43 & - & - & 0,003 & 0,034 & 0,045 & 0,065 \\
\hline Intermediário Adjacente & 2 & - & - & 0,003 & - & - & 0,003 \\
\hline Urbano & 10 & - & - & - & 0,017 & 0,007 & 0,010 \\
\hline Entre 5 mil e 20 mil & 115 & $0,3 \%$ & $1,4 \%$ & $3,8 \%$ & $22,3 \%$ & $2,1 \%$ & $9,6 \%$ \\
\hline Rural Adjacente & 59 & - & - & 0,024 & 0,117 & 0,003 & 0,058 \\
\hline Intermediário Adjacente & 18 & - & 0,007 & 0,003 & 0,038 & - & 0,014 \\
\hline Urbano & 38 & 0,003 & 0,007 & 0,010 & 0,069 & 0,017 & 0,024 \\
\hline Entre $20 \mathrm{mil} \mathrm{e} 50 \mathrm{mil}$ & 68 & $1,7 \%$ & $3,8 \%$ & $\mathbf{7 , 9 \%}$ & $7,2 \%$ & - & $2,7 \%$ \\
\hline Rural Adjacente & 2 & - & - & 0,007 & - & - & - \\
\hline Intermediário Adjacente & 19 & 0,003 & 0,014 & 0,024 & 0,014 & - & 0,010 \\
\hline Urbano & 47 & 0,014 & 0,024 & 0,048 & 0,058 & - & 0,017 \\
\hline Entre 50 mil e 100 mil & 25 & - & $1,4 \%$ & $\mathbf{5 , 5 \%}$ & $0,7 \%$ & - & $1,0 \%$ \\
\hline Urbano & 25 & - & 0,014 & 0,055 & 0,007 & - & 0,010 \\
\hline Entre 100 mil e 500 mil & 23 & $0,7 \%$ & $4,8 \%$ & $1,7 \%$ & $\mathbf{0 , 3 \%}$ & - & $0,3 \%$ \\
\hline Urbano & 23 & 0,007 & 0,048 & 0,017 & 0,003 & - & 0,003 \\
\hline Entre 500 mil e 1 milhão & 5 & $0,3 \%$ & $1,4 \%$ & - & - & - & - \\
\hline Urbano & 5 & 0,003 & 0,014 & - & - & - & - \\
\hline Total & 291 & $3,1 \%$ & $12,7 \%$ & $19,6 \%$ & $35,7 \%$ & $7,2 \%$ & $21,6 \%$ \\
\hline Rural Adjacente & 104 & - & - & 0,034 & 0,151 & 0,048 & 0,124 \\
\hline Intermediário Adjacente & 39 & 0,003 & 0,021 & 0,031 & 0,052 & - & 0,027 \\
\hline Urbano & 148 & 0,027 & 0,107 & 0,131 & 0,155 & 0,024 & 0,065 \\
\hline
\end{tabular}

Fonte: Elaboração própria a partir de IBGE (2017).

Constata-se que cerca de $60 \%$ dos municípios que integram as rotas de cicloturismo consolidadas no Brasil no período pré-pandemia possuem até 20 mil habitantes. Da totalidade, mais da metade se classificam como $\mathrm{C}$ e $\mathrm{D}$, demonstrando que oportunidades de investimentos poderiam auxiliar tanto na alavancagem de municípios categorizados como $\mathrm{E}$, quanto daqueles que ainda não estão classificados dentro do Mapa do Turismo. Por outro lado, a baixa representatividade de municípios categorizados como A e B indica que, no geral, para a sustentação das rotas, não necessariamente se utilizam do posicionamento estratégico de destinos indutores na atração e manutenção de fluxos 
turísticos. Nas complexidades das redes de transportes no contexto do turismo doméstico, municípios que se caracterizam como destinos indutores podem ser sintetizados por funções nodais de distribuição de turistas, por meio de estações terminais significativas e estrutura turística, e de origem de viajantes, por conta de suas respectivas concentrações urbanas - sendo impulsionados pelo fortalecimento da tendência para o turismo local (OMT, 2020b).

Embora as rotas identificadas envolvam 148 municípios urbanos, o somatório dos rurais adjacentes e dos intermediários adjacentes somam 143 municípios, que é bastante significativo para caracterizar a relação entre o cicloturismo como ferramenta do desenvolvimento sustentável do turismo rural no Brasil. Ao se colocar uma lupa no "rural adjacente" envolvendo o número de habitantes dos municípios, nota-se o papel que os municípios com até 5 mil habitantes ( $\mathrm{n}=43$ ) e entre 5 mil e 20 mil habitantes $(n=59)$ apresentam para a consolidação do cicloturismo no Brasil. Para o cicloturismo ser uma ferramenta de desenvolvimento sustentável, é necessário compreender como essas rotas consolidadas antes da pandemia integravam o urbano e o rural.

De todas as 31 rotas identificadas, somente duas envolvem apenas municípios urbanos: Caminho do Sol (SP) e Circuito Costa Verde e Mar (SC). Em uma investigação mais aprofundada sobre o relacionamento do grau de urbanização destas duas rotas, denota-se a preocupação do próprio traçado do percurso de fugir dos centros urbanos durante o trajeto para propiciar maiores momentos de introspecção e contato com a cultura local e paisagens pelo caminho. A exemplificar diretamente por citações das páginas oficiais de cada rota, a primeira afirma que "em quase sua quase totalidade, somente por áreas rurais" (CAMINHO DO SOL, 2020), enquanto a segunda se propõe a entrelaçar o urbano e o rural como a própria atratividade do destino ao destacar a presença de "praias badaladas" no litoral e de "paisagem dos arrozais e as casas de madeira" dando "o tom da viagem" no interior (CITMAR, 2021).

Para uma visualização geral de todas as rotas identificadas, a Figura 3 apresenta produtos da metodologia adotada que evidenciam justamente a sinergia que precisa ocorrer entre cicloturismo e espaço rural. O mapa (a) distribui os municípios integrantes das rotas identificadas por tipologia ruralurbana e o mapa (b) gradua os municípios por rotas presentes em seus territórios. 
CICLOTURISMO COMO FERRAMENTA DE

Figura 3 - Tipologia rural-urbana por município integrante de rotas de cicloturismo identificadas

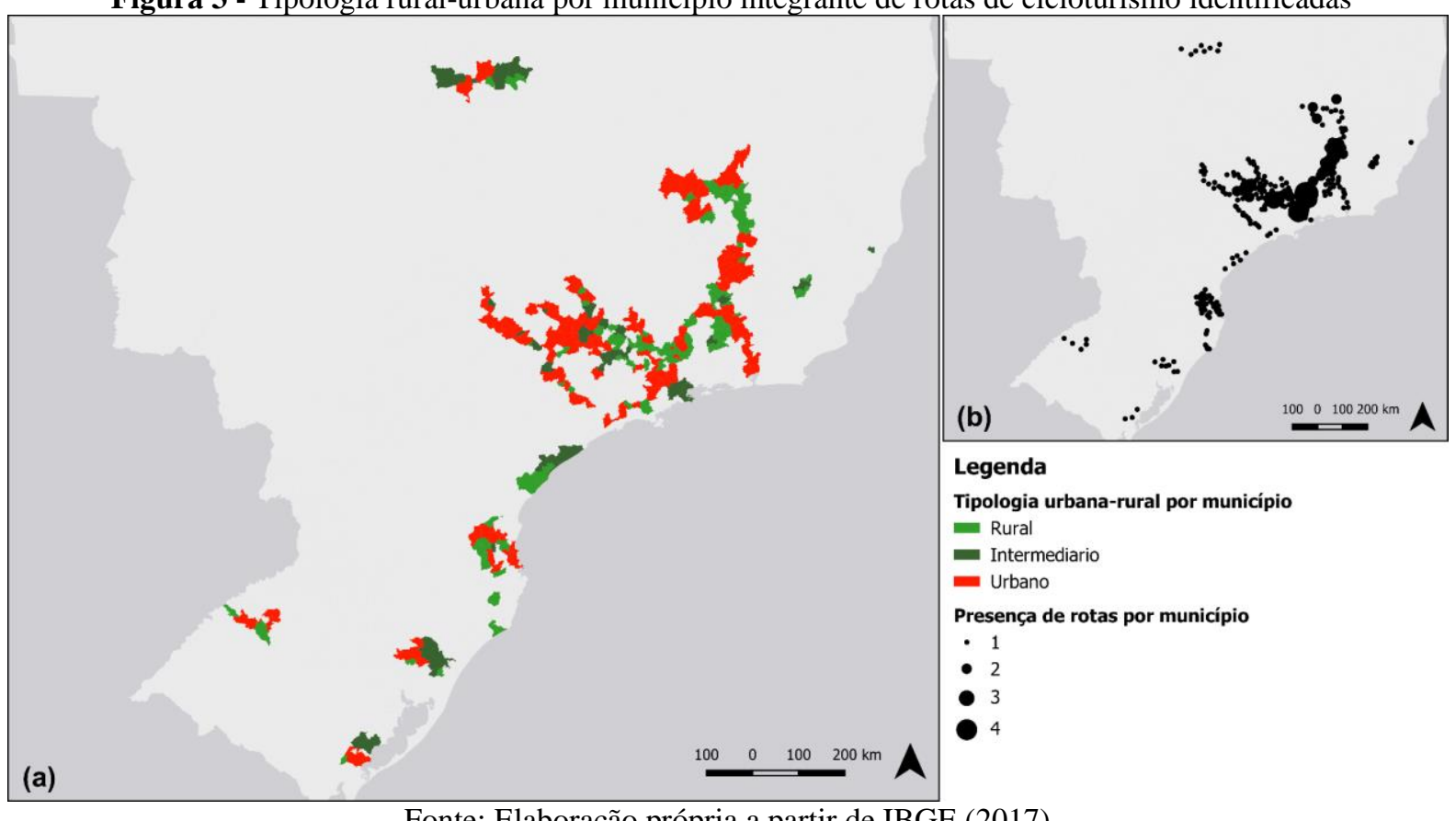

Fonte: Elaboração própria a partir de IBGE (2017).

A finalidade da visualização geral obtida pelo mapa (a) é o auxílio na orientação de investimentos e na elaboração de estratégias para fomentar o turismo rural sem a necessidade de sobrecarregar e impactar negativamente as pequenas cidades, espaços rurais e comunidades tradicionais. A potencialização de funções nodais das redes de transportes deve ter em vista os modelos para planejamento de centros urbanos no contexto do cicloturismo apresentados na seção 2. Faz-se necessária a integração das rotas de cicloturismo a destinos adjacentes com terminais de acesso nacionais ou estaduais (rodoviárias, aeroportos e portos) por meio de políticas cicloinclusivas de implementação e gestão destes terminais, além de infraestrutura viária, estações e veículos de transporte público intrarregional e serviços de turismo e apoio relacionados à atividade. Assim, permite-se a melhora da experiência de cicloturistas e residentes em toda a extensão da rota, deixando aos primeiros apenas a preocupação em pedalar e vivenciar os atrativos tangíveis e intangíveis dos destinos.

Observa-se, a partir do mapa (b), que os quinze municípios que abrangem três ou quatro rotas dentro de seus limites se encontram no estado de São Paulo ou de Minas Gerais. Entre os que estão envolvidos em quatro rotas, todos são classificados como urbanos e possuem categorias mais altas dentro do Mapa Turismo, a saber: Aparecida (A), Guaratinguetá (B), Caxambu (B) e Baependi (C). O destaque principal se dá ao primeiro citado, o qual possui um dos marcos do turismo de peregrinação no Brasil - o Santuário Nacional de Nossa Senhora Aparecida - e, por isso, é posicionado como destino fim 
das quatro rotas integradas a ele (Caminho da Fé, Caminho de Aparecida, CRER e Rota da Luz SP), fora outros trajetos informais ou em construção realizados eventualmente durante o ano. Em relação aos onze municípios abrangidos por três rotas, somente um se encontra no estado de São Paulo e três se classificam como urbanos. A representatividade no cicloturismo também se traduz na organização para a categorização destes municípios no Mapa do Turismo, no entanto, com cerca de dois terços na categoria D e com a respectiva população abaixo de 20 mil habitantes. Os dois municípios categorizados como B (restando outros dois na categoria C), por exemplo, possuem tipologia urbana e centros urbanos mais densos, como São Lourenço (41.652 habitantes) e Pindamonhangaba (146.995 habitantes) (BRASIL, 2021; IBGE 2017).

A sobreposição de rotas em um mesmo município pode ser tida como oportunidade ou ameaça, a depender de como a articulação interna e externa se desenvolve em cada caso. Caso haja uma cooperação entre a gestão das rotas sobrepostas, alinhando interesses e conciliando a atuação dos atores presentes no território para a atividade como um todo, a diversificação da oferta pode influenciar positivamente na taxa de retorno da demanda, assim como na redução da sazonalidade e na geração de novos negócios locais. Para cenários de competição ou falta de diálogo harmonioso entre as partes, a ameaça de haver um declínio para uma ou mais rotas (ou até mesmo para o município como destino de cicloturismo) é elevada. Consequências podem vir, por exemplo, por falta de coerência em sinalização - confundindo os usuários da rota, seja por falta de comunicação junto às comunidades locais - ou pela falta da sensação de pertencimento destas pelas rotas, as quais comprometem ações como manutenção da estrutura e amparo ao visitante.

Este item trouxe a perspectiva que a consolidação das rotas de cicloturismo auxilia também na consolidação da relação entre urbano e rural no Brasil. Ao mesmo tempo, promove a ampliação do espaço turístico brasileiro a partir das ruralidades, sendo o urbano um suporte para que estas aconteçam, mas não necessariamente uma parte essencial para que estas rotas subsistam. Por outro lado, os municípios categorizados como A e B podem contribuir decisivamente para a nacionalização e internacionalização do cicloturismo em áreas rurais, desde que se respeite preceitos básicos como capacidade de carga dos destinos, o que muitas vezes conta com menos de cinco mil habitantes.

\subsection{Desafios e oportunidades na construção de ambientes favoráveis para o cicloturismo}

Apesar da pandemia causada pela COVID-19 ter colocado em curso o "novo normal", esta é antecedida pela crise do turismo enquanto uma indústria que apresenta graves problemas relativos ao 
desenvolvimento sustentável. Dentro deste contexto, a finalidade deste item é alinhar a Agenda 2030 da ONU na construção de ambientes favoráveis para o cicloturismo em áreas rurais. Assim, planejadores, gestores e pesquisadores interessados em ir além do exposto neste estudo podem direcionar esforços a fim de manter o que já se consolidou ou desenvolver o que ainda se encontra em fase de estruturação e envolvimento. A compreensão sobre os documentos dedicados aos ODS pela perspectiva da bicicleta (ECF, 2016; UCB, 2016) e do turismo rural (OMT, 2020a) levantou, por meio da contextualização dos impactos da pandemia na América Latina (BÁRCENA, 2020), a oportunidade de estabelecer a resiliência dos espaços rurais no Brasil. O desafio permanece na articulação de políticas integradas e colaborativas para que se respeite às necessidades e vontades das respectivas comunidades locais de preservar as paisagens do entorno.

Por meio das áreas temáticas das políticas cicloinclusivas apresentadas na Tabela 2 (BID, 2015) e das dinâmicas expostas no cenário do cicloturismo nacional, foi possível realizar um diálogo transversal entre os documentos dedicados aos ODS pelas perspectivas da bicicleta e do turismo rural (ECF, 2016; UCB, 2016; OMT, 2020a):

a. Aspectos normativos e regulação: A proposição de uma abordagem entre todos os níveis de governo (municipal, estadual e nacional) é relevante no favorecimento de marcos regulatórios para fomento e adequação de incentivos, orientação, parcerias e investimentos na consolidação do cicloturismo em áreas rurais. A abertura de diálogos entre setores condiciona efeitos positivos oriundos da interface entre bicicleta e turismo desde a descarbonização das cidades até a geração de renda na escala local. Para isso, o posicionamento do turismo como um dos pilares estratégicos para a gestão de áreas rurais na perspectiva de afirmação da identidade destes destinos é fundamental para envolvimento de políticas de mobilidade ativa na distribuição da atividade pelo território de forma inclusiva e sustentável. O estabelecimento de diretrizes e normas para permitir o uso do solo de modo adequado não apenas favorecerá a preservação contínua de reservas naturais e recursos histórico-culturais tangíveis e intangíveis, como atrairá cada vez mais visitantes focados em experimentar e vivenciar, de modo a respeitar esses limites. Como já discutido neste artigo, o cicloturismo se fortalece pela tendência acelerada por conta do contexto da COVID-19 na busca por atividades ao ar livre e espaços menos densos. O aumento do interesse por um turismo local, mais ético e responsável confirma a oportunidade de sensibilização e mobilização de todos os atores do poder público, além da 
iniciativa privada e da sociedade civil para a criação de um processo de governança colaborativo que execute e monitore os diferentes aspectos locais e regionais do cicloturismo.

b. Participação cidadã: Na visão de governança do cicloturismo em áreas rurais, a adoção de parcerias público-privada-comunitária se faz no engajamento de todas as partes interessadas, desde o desenho do projeto à implementação e coordenação. A participação comunitária não deve seguir a simples consulta ou compartilhamento de informação, mas ter o protagonismo na iniciativa de ação e avaliação dos projetos de turismo e domínio sobre a propriedade e gestão de empreendimentos e serviços que atenderão aos visitantes (FABRINO; NASCIMENTO; COSTA, 2016). Por exemplo, para definição das rotas principais e alimentadoras que sirvam à população não apenas para atividades de turismo e lazer, é de suma importância a aplicação de tecnologias sociais como a utilizada no projeto Ciclo Rotas Centro (MARQUES, 2016) para mapeamento das linhas de desejo de ciclistas. A pluralidade existente para a representatividade comunitária, contudo, deve ser levada em consideração para a distribuição igualitária dos benefícios à região, de modo que grupos mais vulneráveis não sejam excluídos das tomadas de decisão. O turismo deve ser visto como um elemento complementar às soluções locais e regionais de desenvolvimento socioeconômico e, de forma alguma, deve ser percebido ou implementado de maneira impositiva. A identificação de lideranças locais deve passar também por todas as populações tradicionais existentes e atuantes em determinado território para compreensão e proposição do melhor alinhamento sobre os arranjos produtivos envolvidos na experiência do cicloturismo - do turismo receptivo ao fornecimento de produtos agroecológicos nos estabelecimentos do destino. Por fim, ações de capacitação e comunicação interna possuem papel relevante na sensação de pertencimento dos residentes em relação à rota de cicloturismo implementada, garantindo a manutenção espontânea e continuidade do projeto para a região.

c. Infraestrutura e serviços: O cicloturismo pode servir como catalisador de investimentos na conexão de centros urbanos a áreas rurais, e entre diferentes áreas rurais, por meio de infraestrutura cicloviária. Reforça-se o entendimento sobre este tipo de infraestrutura, que não se restringe apenas a ciclovias e ciclofaixas, mas ao estabelecimento de condições seguras, atraentes e coerentes para ciclistas se deslocarem por rodovias principais, estradas e vias vicinais com pouco ou nenhum fluxo de veículos motorizados e ruas de acesso a zonas periféricas de cada localidade. Com a promoção da atividade turística por bicicleta, a utilização de elementos 
CICLOTURISMO COMO FERRAMENTA DE

ÁREA RURAL: DESAFIOS E OPORTUNIDADES

NO PROCESSO DE RETOMADA PÓS-

PANDEMIA DA COVID-19

para redução de conflitos com veículos motorizados melhora significativamente a percepção de segurança pública e a sinalização para fácil orientação sem diminuição ou quebra do ritmo da pedalada. Tais benefícios para a população rural são definidos por acesso a bens e serviços utilitários (e.g. trabalho, educação e comércio) sem a dependência de transporte motorizado individual e coletivo, por facilitar a distribuição de produtos agroecológicos a receptores nos centros urbanos. Intrínseco à infraestrutura física necessária para o cicloturismo existir, a demanda por serviços de funcionamento e de apoio a esta atividade oportuniza a geração de renda e criação de negócios decentes e justos para grupos vulneráveis (povos tradicionais, mulheres, crianças e idosos). Assim, promovem-se microempreendimentos baseados na economia familiar relacionados à aquisição de produtos ou a vivências em gastronomia, artesanato, agricultura, bem-estar, entre outros. Outro atributo significativo para aumento da qualidade da experiência do visitante e da comunidade receptora é a garantia da conectividade à internet das áreas rurais. $\mathrm{O}$ acesso às Novas Tecnologias da Informação e Comunicação (NTICs) contribuirá também para a segurança e preservação das paisagens naturais e sítios histórico-culturais - como gestão de acesso e controle de capacidade em áreas comuns, por exemplo.

d. Gestão, controle e operação: A governança para a rota de cicloturismo estabelecida por meio da participação cidadã e dos aspectos normativos e regulação torna disponível, regularmente, as informações atualizadas sobre infraestrutura e serviços em formato acessível para comunicação interna e externa. A fim de fomentar políticas a iniciativas baseadas em evidências, deve-se buscar instrumentos de coleta e métodos de análise estatísticas eficientes para produção de dados confiáveis. Na perspectiva de digitalização de áreas rurais, as oportunidades de sistematização de informações geradas espontaneamente são amplificadas e podem ser conduzidas em parcerias junto à iniciativa privada e academia. A maximização do uso de NTICs é posicionada estrategicamente para mensuração do padrão de fluxos de cicloturistas e para compreensão sobre o respectivo perfil sociodemográfico, hábitos de viagem e avaliação pósvisita. Em nível local, requer-se um monitoramento sistemático sobre a atividade nas áreas de acessibilidade, sazonalidade, impactos socioeconômicos, satisfação comunitária e na gestão de energia, água e resíduos. 
Espera-se que, principalmente no contexto de cidades com até 20 mil habitantes, tomadores de decisão e membros de comunidades possam se engajar no preparo de destinos nesta geomorfologia para um êxodo urbano cada vez mais significativo nos momentos de turismo e lazer. Respeitando o primeiro enfoque, que é manter consolidado o que já estava posto no pré-pandemia, observa-se que há necessidades de políticas públicas relativas ao turismo, sustentabilidade e o uso de bicicletas para que se fortaleça as rotas de cicloturismo. As políticas integradas visando o baixo impacto ambiental, o detalhamento do estudo da demanda e o uso da população podem mitigar as ameaças externas à atividade e potencializar as oportunidades.

\section{Considerações Finais}

As oportunidades e os desafios no processo de retomada do turismo pós-pandemia do COVID 19 são inúmeras. Nesse sentido, o objetivo do presente estudo foi analisar o cicloturismo como ferramenta para o desenvolvimento sustentável de áreas rurais no Brasil. A pesquisa de cunho exploratório e descritivo revelou, a partir da revisão da literatura e da parte empírica baseada em dados secundários, o mapa das rotas de cicloturismo consolidadas pré-pandemia e a classificação e caracterização dos municípios abrangidos. Além disso, por meio da contextualização dos resultados a partir da Agenda 2030 e da Covid-19 pode-se inferir que os resultados contribuem para avançar nas quatro áreas temáticas das políticas cicloinclusivas: (1) aspectos normativos e regulação; (2) participação cidadã; (3) infraestrutura e serviços; (4) gestão, controle e operação.

Além disso, numa perspectiva holística, o cicloturismo pode, inclusive, contribuir para conter o êxodo rural em municípios de até 5 mil habitantes, ou naqueles de até 20 mil habitantes, já que esses são essenciais para que as rotas de cicloturismo se mantenham consolidadas na retomada do turismo pós-pandemia. Embora os impactos negativos sejam inúmeros, são espaços rurais que apresentam a força significativa para manter as rotas consolidadas e são os municípios categorizados como C e D que podem dar suporte às dinâmicas de retomada do cicloturismo em áreas rurais em nível nacional. Por outro lado, a internacionalização do cicloturismo brasileiro nas áreas rurais depende essencialmente do envolvimento de pontos de apoio em municípios que são A e B, mesmo que estes estejam fora das rotas.

Os municípios que não são categorizados como turísticos podem criar um diferencial futuro para a diversificação da oferta do cicloturismo em áreas rurais no Brasil, uma vez que esses ainda não receberam atenção por parte das políticas públicas de turismo para tornar seus recursos em atrações turísticas, mas que já têm as rotas como parte de sua atratividade. Sendo assim, esse é um dos principais 
desafios futuros da ampliação, de maneira sustentável, do espaço turístico brasileiro envolvendo cicloturismo e ruralidades. Por fim, destaca-se, entre as limitações do estudo, a abordagem com dados secundários que estruturaram a investigação sobre as rotas de forma autodeclarada e recomenda-se que futuros estudos possam aprofundar análises nacionais ou regionalizadas a partir de dados primários.

\section{Referências}

BÁRCENA, A. La Agenda 2030 y la Década de la Acción Perspectivas desde América Latina y el Caribe. Comisión Económica para América Latina y el Caribe. CEPAL: Santiago de Chile, 2020.

BID. BANCO INTERAMERICANO DE DESENVOLVIMENTO. Ciclo-inclusión en América Latina y el Caribe: Guía para impulsionar el uso de la bicicleta. Cidade do México: BID, 2015.

BRASIL. Categorização dos Municípios das Regiões Turísticas do Mapa do Turismo Brasileiro. Perguntas e Respostas. Ministério do Turismo: Brasília, 2019. Disponível em: http://www.regionalizacao.turismo.gov.br/images/conteudo/Perguntas_espostas_Categorizacao_2019. pdf. Acesso em: 28 set. 2021.

BRASIL. Mapa do Turismo 2019-2021. Disponível em: http://www.mapa.turismo.gov.br/mapa/init.html. Acesso em: 28 set. 2021.

CAMINHO DO SOL. História. Caminho do Sol. 2020. Disponível em: http://www.caminhodosol.org.br/historia.aspx. Acesso em: 13 jul. 2021.

CARVALHO, T.J.L; RAMOS, J.L.; SYDOW, E. O cicloturismo como fator de desenvolvimento da atividade turística nas cidades de Araguaína e Nova Olinda (TO). Anais do IX Congresso Nacional de Ecoturismo e do V Encontro Interdisciplinar de Turismo em Unidades de Conservação. Revista Brasileira de Ecoturismo, São Paulo, v. 6, n. 4, p. 63-82, 2013.

CICLOTUR EXPERIENCE. Página inicial. Ciclotur Experience. Disponível em: https://ciclotur.com.br/. Acesso em: 29 abr. 2020.

CITMAR. CONSÓRCIO INTERMUNICIPAL DE TURISMO COSTA VERDE E MAR.

Cicloturismo. 2021. Disponível em: https://costaverdemar.com.br/novo/cicloturismo/. Acesso em: 13 jul. 2021.

CLUBE DE CICLOTURISMO DO BRASIL. Roteiros. Clube de Cicloturismo do Brasil. Disponível em: <http://www.clubedecicloturismo.com.br/roteiros>. Acesso em: 29 abr. 2020.

ECF. EUROPEAN CYCLISTS' FEDERATION. Cycling Delivers on the Global Goals: Shifting towards a better economy, society, and planet for all. ECF: Bruxelas, 2016.

FABRINO, N. H.; NASCIMENTO, E. P. E; COSTA, H. A. Turismo de Base comunitária: uma reflexão sobre seus conceitos e práticas. Caderno Virtual de Turismo, Rio de Janeiro, v. 16, n. 3, p. 172-190, 2016. 
FONTOURA, L.; LUSBY, C.; ROMAGOSA F. Post-COVID-19 tourism: perspectives for sustainable tourism in Brazil, USA and Spain. Revista Acadêmica Observatório de Inovação do Turismo, Rio de Janeiro, v. 14, p. 16-28, 2020.

FRAGA, C.; SANTOS, M.P.S.; RIBEIRO, S. Construindo perguntas sobre o papel dos transportes terrestres para o desenvolvimento sustentável do turismo rural no Vale do Café. In: LOHMANN, G.; FRAGA, C.; CASTRO, R. Transportes e Destinos Turísticos: Planejamento e Gestão. Rio de Janeiro: Elsevier, 2013.

IBGE. INSTITUTO BRASILEIRO DE GEOGRAFIA E ESTATÍSTICA. Classificação e caracterização dos espaços rurais e urbanos do Brasil: uma primeira aproximação. IBGE, Coordenação de Geografia. - Rio de Janeiro: IBGE, 2017.

IBGE. INSTITUTO BRASILEIRO DE GEOGRAFIA E ESTATÍSTICA. Publicação 2020.2: População das Regiões Metropolitanas, Regiões Integradas de Desenvolvimento e Aglomerações Urbanas com mais de um milhão de habitantes. Brasília: IBGE, 2020.

LAMONT, M. Independent bicycle tourism: A whole tourism systems perspective. Tourism Analysis, v. 14, n. 5, 2009.

LEE, C. F. An investigation of factors determining cycling experience and frequency. Tourism Geographies, v. 16, n. 5, 2014.

LÉVY, P. O que é virtual? São Paulo: Editora 34, 1996.

LOHMAnN, G.; PANOSSO NETTO, A. Teoria do Turismo. São Paulo: Aleph, 2008.

LOHMANN, G.; DUVAL, D. T. Destination morphology: A new framework to understand tourismtransport issues? Journal of Destination Marketing \& Management, v. 3, p. 133-136, 2014.

MARQUES, R. Ciclo Rotas Centro será um dos projetos brasileiros na Bienal de Arquitetura de Veneza. ITDP Brasil. 2016. Disponível em: https://itdpbrasil.org/ciclo-rotas-centro/. Acesso em: 8 set. 2021.

MILANO, C.; KOENS, K. The paradox of tourism extremes. Excesses and restraints in times of COVID-19. Current Issues in Tourism, v. 24, p. 1-15, 2021.

OMT. ORGANIZAÇÃO MUNDIAL DO TURISMO. UNWTO Recommendations on Tourism and Rural Development - A Guide to Making Tourism an Effective Tool for Rural Development. Madri: OMT, 2020a.

OMT. ORGANIZAÇÃO MUNDIAL DO TURISMO. Understanding Domestic Tourism and Seizing its Opportunities. Madri: OMT, 2020b.

ONU. ORGANIZAÇÃO DAS NAÇÕES UNIDAS. Objetivos do Desenvolvimento Sustentável. 2015. Disponível em: https://nacoesunidas.org/pos2015/agenda2030/. Acesso em agosto de 2021.

PALHARES, G.L. Transportes para turistas: conceitos, estado da arte e tópicos atuais. In: TRIGO, L.G.G. (org.). Análises globais e regionais do turismo brasileiro. São Paulo: Rocca, p. 641-669, 2005. 
PSF. PEREGRINOS SEM FRONTEIRAS. O Brasil e seus caminhos. Peregrinos Sem Fronteiras. Disponível em: https://www.peregrinosemfronteiras.com.br/caminhos-do-brasil. Acesso em: 29 abr. 2020.

REVISTA BICICLETA. Cicloturismo. Revista Bicicleta. Disponível em: https://revistabicicleta.com/categoria/cicloturismo/. Acesso em: 29 abr. 2020.

SALDANHA, L. Políticas Cicloinclusivas e Cicloturismo: O caso do Rio de Janeiro. Programa de Engenharia de Transportes. Dissertação de Mestrado. Rio de Janeiro: Universidade Federal do Rio de Janeiro, 2017.

SALDANHA, L.; DECASTRO, J.; SOUZA, H. A. S.; TELLES, R.; GARCIA, E.; AMARAL, J. P. E; BALASSIANO, R. O Cicloturista Brasileiro 2018: relatório geral. Rio de Janeiro: Coppe-UFRJ, 2019.

SALDANHA, L.; FREITAS, L.; BALASSIANO, R.; FRAGA, C. Cicloturismo no planejamento integrado das cidades e o caso da região metropolitana de Curitiba. Revista Turismo em Análise, v. 31, n. 2, p. 296-315, 2020.

SALDANHA, L.; SOUZA, H. A. S.; DECASTRO, J.; FREITAS, L. P.; BALASSIANO, R. O cicloturismo como indutor de desenvolvimento na região turística da Costa do Sol, Rio de Janeiro, Brasil. Anais do 9o. Congresso Luso-Brasileiro para o Planejamento Urbano, Regional, Integrado e Sustentável (PLURIS 2021 DIGITAL). Águas de Lindoia: Unesp, 2021.

SARTORI, A. O evento ciclístico "Pedala Trento" e suas contribuições para o cicloturismo em Nova Trento/SC e região. Revista Acadêmica Observatório de Inovação do Turismo, Rio de Janeiro, v. 14, n. 3, p. 1-23, 2020.

SBPC. 73 ${ }^{\text {a }}$ Reunião Anual da SBPC. Disponível em: http://portal.sbpcnet.org.br/eventos/73areuniao-anual-da-sbpc/ Acesso em 28 nov. 2021.

SOUSA, R. O. C.; CARVALHO, K. D. Cicloturismo como promotor do desenvolvimento de áreas rurais: possibilidades na regiõ do Baixo Parnaíba Maranhense. Revista Turismo, Visão e Ação. Univali, v. 23, n. 2, p. 329-349, 2021.

TULIK, O. (2004). Turismo Rural. Coleção ABC do Turismo. 2 ed. São Paulo: Aleph.

UCB. UNIÃO DE CICLISTAS DO BRASIL. A bicicleta como promotora dos 17 ODS: Contexto brasileiro. UCB: Brasil, 2016.

VERÍSSIMO, M.; MORAES M.; BREDA, Z..; GUIZI, A.; COSTA, C. Overtourism and tourismphobia: A systematic literature review. Tourism: An International Interdisciplinary Journal. UDC, v. 68, n. 2, p. 156-169, 2020.

WESTCYCLE. Western Australian: Cycle tourism strategy. Tourism Western Australia. WestCycle Incorporated: Perth, 2016.

WIECKOWSKI, M. Will the Consequences of Covid-19 Trigger a Redefining of the Role of Transport in the Development of Sustainable Tourism? Sustainability, v. 13, 1887, p.1-15, 2021.

Revista Acadêmica Observatório de Inovação do Turismo, v. 15, n. 3, dezembro/2021 